\title{
La evolución de Ixtapa-Zihuatanejo, México, desde el modelo del ciclo de vida del destino turístico
}

\author{
Evolution of Ixtapa-Zihuatanejo, Mexico, \\ from the life cycle as a tourism destination model
}

\author{
Maribel Osorio García* (D) https://orcid.org/0000-0002-3336-6231 \\ Marie Eugenie Deverdum Reyna** (D) https://orcid.org/0000-0003-1391-3995 \\ Martha Marivel Mendoza Ontiveros ${ }^{* * *}$ (D) https://orcid.org/0000-0003-2492-0760 \\ Jazmín Benítez López ${ }^{* * * *}$ (D) https://orcid.org/0000-0002-2734-5012
}

\begin{abstract}
Resumen
El objetivo de este artículo es analizar el Centro Integralmente Planificado de Ixtapa-Zihuatanejo, para distinguir la condición que prevalece en su evolución, de acuerdo con el modelo del ciclo de vida como destino turístico de Butler. Se retoma la metodología aplicada por la Comisión Europea, para demostrar que en la actualidad se registran signos claros de declive, tales como la recomposición de los flujos turísticos y el comportamiento a la baja de los indicadores de la estadía, la estacionalidad y la ocupación. Aunque no existe información estadística para trabajar todos los indicadores requeridos por la metodología, se logran caracterizar los factores exógenos y endógenos, que han influido en la trayectoria, y los cambios y las problemáticas generados. Se concluye que Ixtapa-Zihuatanejo detuvo su desarrollo planificado como destino turístico internacional a principios del siglo XXI, cuando comenzó a mostrar signos de declive y cambió su dinámica de destino internacional a nacional.

Palabras clave: destinos turísticos; ciclo de vida; desarrollo turístico; Ixtapa-Zihuatanejo.
\end{abstract}

\begin{abstract}
This article's purpose is to analyze the Integrally Planned Center of Ixtapa-Zihuatanejo in order to distinguish the status prevailing in its evolution, according to Butler's life cycle as a tourism destination model. The methodology applied by the European Commission is used in order to demonstrate that there are currently clear signs of decline, such as the reconfiguration of tourism flows and the decrease in the stay, seasonality and occupancy indicators. Although there is no statistical information available to work with the indicators required by methodology, the exogenous and endogenous factors, which have influenced the trajectory, as well as the changes and problems generated, are characterized. It follows that Ixtapa-Zihuatanejo's planned development halted as an international tourism destination at the beginning of the 2 Ist century, when it started to show signs of decline and it changed its dynamics from an international destination to a national one.

Keywords: tourism destinations; life cycle; tourism development; Ixtapa-Zihuatanejo.
\end{abstract}

Cómo citar: Osorio García, M., Deverdum Reyna, M. E., Mendoza Ontiveros, M. M., y Benítez López, J. (20I9). La evolución de Ixta-

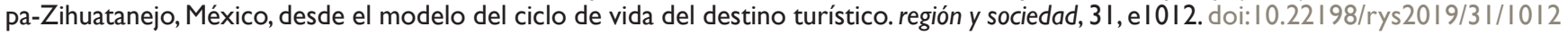

* Autora para correspondencia. Universidad Autónoma del Estado de México, Facultad de Turismo y Gastronomía. Ciudad Universitaria s/n, Cerro de Coatepec, C. P. 50100. Toluca, Estado de México, México. Correo electrónico: maribelosorio2@gmail.com

** Universidad Autónoma del Estado de México, Facultad de Turismo y Gastronomía. Ciudad Universitaria s/n, Cerro de Coatepec, C. P. 50100. Toluca, Estado de México, México. Correo electrónico: genidev80@gmail.com

*** Universidad Autónoma del Estado de México, Centro Universitario Texcoco. Av. Jardín Zumpango s/n, El Tejocote, C. P. 56259 Texcoco, Estado de México, México. Correo electrónico: marivelmo@hotmail.com

**** Universidad de Quintana Roo, Unidad Académica Chetumal. Boulevard Bahía s/n esquina Ignacio Comonfort, colonia Del Bosque, C. P. 77019 Chetumal, Quintana Roo, México. Correo electrónico: jazminb@uqroo.edu.mx

Recibido: 14 de diciembre de 2017

Aceptado: 10 de mayo de 2018

Liberado: 13 de febrero de 2019 


\section{Introducción}

La movilidad del turismo es importante para México, en 2016 se contabilizaron 34.9 millones de llegadas de turistas internacionales, de los cuales 20.4 millones fueron de internación (Banco de México, 2017), cuya movilidad se manifestó en los ámbitos regionales y locales de manera diferenciada, y se concentró en los lugares que se eligieron para que se especializaran en turismo extranjero, como parte de la estrategia gubernamental denominada Centros Integralmente Planeados (CIP). Tal es el caso de Ixtapa-Zihuatanejo (I-Z), en el estado de Guerrero, creado en 1974 por el Fondo Nacional de Fomento al Turismo (FONATUR), para desconcentrar el puerto de Acapulco, y ofrecer otro atractivo de sol y playa a este segmento turístico.

La estrategia de planificación integral seguida por FONATUR en los años setenta para crear los CIP, en regiones marginadas con recursos naturales de gran potencialidad, fue aplicada por primera vez en Cancún, en Quintana Roo; en I-Z, Guerrero, y en Loreto y Los Cabos, en Baja California Sur, para detonar desarrollo turístico que generara empleo, captara divisas y propiciara un equilibrio regional (Dávila, 2014), con base en la teoría de los polos de desarrollo industrial de Perraux (Hiernaux, 1985). A este grupo se le sumó Huatulco, Oaxaca, al inicio de la década de 1980. La trayectoria de cada CIP ha sido diferente, Cancún cumplió mayormente la expectativa proyectada, en cambio el éxito de los otros ha sido menor (Secretaría de Turismo [SECTUR], 2000).

El CIP Ixtapa-Zihuatanejo ha sido objeto de estudio de varias investigaciones (Bravo, 1994; Brenner, 1999; Hernández-Lobato, Solís-Radilla, Moliner-Tena y Sánchez-García, 2006; SECTUR, 2012, 2013), que han aportado análisis sobre los alcances y las limitaciones que se observan en su proceso de desarrollo turístico. En 2012, SECTUR evaluó el desempeño de 50 destinos, y ubicó a I-Z en una etapa de "desarrollo" (2012, p. 207), de acuerdo con el modelo del ciclo de vida del destino turístico (CVDT), de Butler, y obtuvo un índice de desempeño turístico de 3.04 (de un rango máximo de 17.4 y mínimo de -2.8), se colocó en el lugar 16 de todos los destinos considerados en el estudio. Ubicar a I-Z en una etapa de desarrollo implica que su evolución se encuentra en una fase de crecimiento, previa al momento de consolidación, al menos en la lógica del modelo mencionado.

El CVDT se ha utilizado profusamente, para dimensionar los cambios en los espacios turísticos de localidades o regiones (García, Reinares y Armelini, 2012), para caracterizar la etapa de evolución en la que se encuentran y conocer los beneficios y perjuicios generados por ésta. Investigaciones recientes en China (Yang, Ryan y Zhang, 2014), Grecia (Michailidou, Vlachokostas, Moussiopoulos y Maleka, 2016), España (García-Ayllon, 2015), Malasia (Shida, Abdul, Badaruddin y Azizi, 2015) y Korea (Lee y Weaver, 2014) han aplicado dicho modelo como soporte teórico explicativo para sus diagnósticos. De esta manera, pese a sus críticas, el CVDT continúa siendo una herramienta útil para identificar la situación de los destinos de acuerdo con su etapa de evolución y da pie para plantear dos cuestionamientos: ¿se encuentra I-Z en una trayectoria de desarrollo o de declive?, y ¿qué problemáticas económicas, urbanas, ambientales y sociales se han producido en su trayectoria? El objetivo de este artículo es analizar el CVDT 
de I-Z para distinguir la condición que prevalece en su trayectoria, los factores exógenos y endógenos que han influido en ella y los cambios y las problemáticas generados. El texto consta de tres apartados, el primero expone el modelo del CVDT, se caracteriza a cada etapa y se mencionan las críticas principales que se le han hecho. El segundo incluye la metodología, con la descripción de la investigación documental y la de campo, que se dividen en dos líneas de análisis, para corresponder a las preguntas de investigación. En el tercero están los hallazgos, divididos también en dos líneas de análisis: las etapas y los factores del CVDT, y los cambios y las problemáticas en I-Z y, por último, las conclusiones.

\section{El modelo del CVDT: planteamiento y críticas}

El CVDT se originó en un artículo de Richard Butler (1980), y representa uno de los paradigmas esenciales en torno al desarrollo de los destinos turísticos (Harrison, 1995; Lundtorp y Wanhill, 2001). Christaller (1964) ya había identificado estadios en el progreso de los destinos turísticos en cuyo crecimiento se detectaban ciertas regularidades. Alimentado con el modelo del ciclo de vida del producto y con los de población de la vida salvaje, Butler (2006) diseñó uno para explicar las trasformaciones de los destinos turísticos, para lo que tomó, como criterio fundamental, la capacidad de carga para definir sus etapas (ver Tabla 1).

En las etapas de exploración e implicación se establece que la capacidad de carga es menor al total de habitantes; en las de desarrollo, consolidación y estancamiento, el número de turistas excede al total de habitantes durante la temporada alta. De acuerdo con Butler (2012), los cambios en la evolución hipotética del CVDT son producidos por factores exógenos y endógenos. Los primeros constituyen la dinámica del destino y se vinculan con la política, la tecnología y la economía, entre otros; los segundos conforman la sinergia, y se corresponden con las trasformaciones en la infraestructura, la demanda y la oferta turísticas.

Según el modelo, en la etapa de desarrollo es cuando los cambios generados por la intervención gubernamental planificada y el dinamismo procedente de inversiones externas detonan el crecimiento del destino, hasta hacerlo figurar en el mercado turístico. A partir de aquí, la inercia lo conduce a la consolidación, reconocida por el carácter internacional de su demanda y empresas turísticas, hasta que dicha inercia genera una entropía que modifica las condiciones iniciales favorables.

Las críticas en torno a las limitaciones del modelo de Butler han sido profusas (Aguiló, Alegre y Sard, 2005; Ap, 1992; Bianchi, 1994; Deery, Jago y Fredline, 2012; Haywood, 1986; López, 2011; Lundtorp y Wanhill, 2001; Ma y Hassink, 2013; McKercher, 1999, 2005; Russel y Faulkner, 1999; Soares, Gandara e Ivars, 2012; Vera et al., 2013). Sus señalamientos principales están relacionados con: a) la falta de claridad sobre la forma de medir la capacidad de carga y su insuficiencia como indicador general de los cambios; b) la imprecisión de los criterios e indicadores para definir cada etapa; c) la ausencia explicativa de su conexión con los aspectos de mercadotecnia y competitividad; d) la estandarización del 
comportamiento empresarial; e) la desconsideración de las particularidades del espacio para entender la trayectoria del destino y f) la fundamentación epistemológica de la evolución, con base en un paradigma lineal cartesiano. Para superar dichas críticas, Butler (2011) y otros teóricos (Agarwal, 2002; Diedrich y García-Buades, 2009; Garay y Cánoves, 2011; Getz, 1992; Kozak y Martin, 2012; Kristjánsdóttir, 2016; López-Bonilla y López-Bonilla, 2008; Ma y Hassink, 2013, Soares et al., 2012) han conjuntado teorías y metodologías para llenar los vacíos del modelo original del CVDT, fortalecer su rigurosidad y superar sus limitaciones.

Tabla 1. Etapas del modelo de CVDT

\begin{tabular}{|c|c|}
\hline Etapa & Características \\
\hline Exploración & $\begin{array}{l}\text { - Arriba un número reducido de personas } \\
\text { - El destino es poco accesible y sin equipamiento }\end{array}$ \\
\hline Implicación & $\begin{array}{l}\text { - Aumenta el número de turistas } \\
\text { - Apertura de empresas de iniciativa local } \\
\text { - Distinción de un nuevo mercado en una temporada definida } \\
\text { - Para facilitar la llegada de turistas se le pide al gobierno que } \\
\text { realice mejoras en la infraestructura }\end{array}$ \\
\hline Desarrollo & $\begin{array}{l}\text { - El flujo turístico aumenta en forma exponencial } \\
\text { - El destino se masifica } \\
\text { - Las organizaciones turísticas son promovidas y administradas } \\
\text { por agentes externos a la comunidad } \\
\text { - Se conforma la imagen turística del destino } \\
\text { - El gobierno planifica e invierte en turismo }\end{array}$ \\
\hline Consolidación & $\begin{array}{l}\text { - Los turistas siguen aumentando, pero a menor ritmo } \\
\text { - Predomina la industria turística internacional y de cadena } \\
\text { - El turismo es el sector económico dominante } \\
\text { - Se manifiestan algunos efectos negativos para la población, } \\
\text { que generan descontento }\end{array}$ \\
\hline Estancamiento & $\begin{array}{l}\text { - Se detiene el aumento de turistas, quienes pierden interés } \\
\text { en el destino } \\
\text { - Los atractivos se deterioran y se sustituyen por otros } \\
\text { - Hay problemas económicos, ambientales y sociales } \\
\text { en la comunidad local }\end{array}$ \\
\hline Posestancamiento & $\begin{array}{l}\text { Si se produce un declive: } \\
\text { - Disminuyen los turistas de manera importante y se reduce } \\
\text { - La duración de la estancia } \\
\text { - Las empresas bajan los precios para captar clientes y mantener } \\
\text { - Lu cuota de mercado } \\
\text { a otros usos locales } \\
\text { Si se produce un rejuvenecimiento: } \\
\text { - El destino se revitaliza mediante infraestructuras, atractivos y/o } \\
\text { políticas de mercado nuevos y de aprovechamiento racional }\end{array}$ \\
\hline
\end{tabular}

Fuente: elaboración propia, con base en Butler (2004); Vera, López-Palomeque Marchena y Antón (2013); Deverdum, Osorio y Cenecorta (2016). 
En este artículo la atención se centra en lo señalado por Hovinen (2002), quien demuestra que las etapas no son secuenciales, sino que hay coexistencia entre ellas, incluso entre el crecimiento y el estancamiento, dependiendo del comportamiento de los factores. El declive se identifica cuando un destino de tradición turística presenta un conjunto de signos negativos, tanto de carácter endógeno como exógeno (Comisión Europea, 2004). Soares et al. (2012) desarrollaron una matriz que vincula a las etapas del CVDT con los cambios económicos, socioculturales y ambientales, y ubicaron que en la de exploración el beneficio económico es alto y hay pocos problemas, también que en la de declive el beneficio económico es bajo y hay muchos problemas ambientales y socioculturales. De acuerdo con estas posturas, hay una articulación entre los factores endógenos y exógenos negativos y las problemáticas ambientales y socioculturales que convergen, para identificar que un destino se encuentra en declive.

\section{Metodología}

La investigación se perfiló sobre las consideraciones ya comentadas, en dos líneas de análisis: a) la caracterización de las etapas del CVDT y la identificación de los factores exógenos y endógenos, que otorgan los signos del declive, y b) la referida a los cambios y problemas económicos, urbanísticos, ambientales y sociales que experimenta el destino. Para la identificación de los signos de declive se retoman las categorías establecidas en la metodología de la Comisión Europea (2004, p. 13), que aparecen en la Tabla 2.

Cabe aclarar que en la categoría de las dificultades para garantizar un turismo sostenible se incorporaron, por una parte, las consideraciones de Vera et al. (2013) sobre el crecimiento poblacional y urbano, que se produce con regularidad en destinos turísticos de litoral y, por otra, la variable sobre el empleo (personal ocupado), que se torna estructural en el caso de estudio (Telfer y Sharpley, 2016). Estos elementos enriquecieron el análisis de los cambios y problemas económicos, urbanísticos, ambientales y sociales del destino.

Para obtener información se consultaron documentos oficiales, páginas web y bases de datos estadísticas sobre el comportamiento de la demanda y la oferta turísticas del sistema de información Datatur, de la guía de los indicadores establecidos por Soares et al. (2012, p. 30). Además, se recurrió a los sistemas de información del Instituto Nacional de Estadística y Geografía (INEGI) y del Consejo Nacional de Población (CONAPO), ${ }^{1}$ así como a investigaciones especializadas y documentos oficiales sobre I-Z (Ayuntamiento de Zihuatanejo de Azueta, 2014, 2016; SECTUR, 2012, 2013). La identificación de los ritmos históricos de crecimiento de las variables con información suficiente se calculó con la tasa de crecimiento media anual (TCMA).

INEGI. Proyectos estadísticos. (http://www.beta.inegi.org.mx/datos/?init=2); CONAPO. Dinámica demográfica y proyecciones de población. (http://www.conapo.gob.mx/es/CONAPO/Publicaciones). 
Tabla 2. Categorías y variables de los signos de declive del CVDT aplicadas a I-Z

\begin{tabular}{|c|c|c|c|}
\hline $\begin{array}{l}\text { Factores } \\
\text { exógenos }\end{array}$ & $\begin{array}{l}\text { Disminución del } \\
\text { flujo de visitantes }\end{array}$ & $\begin{array}{c}\text { Disminución de los } \\
\text { elementos que } \\
\text { definían la calidad } \\
\text { del destino }\end{array}$ & $\begin{array}{c}\text { Dificultades para } \\
\text { garantizar } \\
\text { un turismo sostenible }\end{array}$ \\
\hline $\begin{array}{l}\text { - Factores } \\
\text { políticos } \\
\text { (terrorismo y } \\
\text { seguridad) } \\
\text { - Factores } \\
\text { económicos } \\
\text { (crisis) } \\
\text { - Competencia } \\
\text { Publicidad } \\
\text { negativa }\end{array}$ & $\begin{array}{l}\text { - Llegada de } \\
\text { menos turistas } \\
\text { al destino } \\
\text { - Reducción del } \\
\text { número de noches } \\
\text { que los turistas } \\
\text { pasan en el destino } \\
\text { - Disminución } \\
\text { de la media de } \\
\text { días que los turistas } \\
\text { permanecen } \\
\text { en el destino } \\
\text { - Concentración } \\
\text { estacional de flujos }\end{array}$ & $\begin{array}{l}\text { - Cambios en la } \\
\text { composición } \\
\text { de los flujos } \\
\text { de visitantes } \\
\text { - Disminución } \\
\text { de la calidad } \\
\text { de los turistas } \\
\text { que visitan } \\
\text { el destino } \\
\text { - Reducción } \\
\text { de la calidad del } \\
\text { producto turístico }\end{array}$ & $\begin{array}{l}\text { - Económicas } \\
\text { (empleo y poco ingreso) } \\
\text { - Urbanas } \\
\text { (crecimiento de población } \\
\text { y vivienda, asentamientos } \\
\text { irregulares) } \\
\text { - Ausencia de } \\
\text { infraestructura } \\
\text { y suministro adecuados } \\
\text { - Materiales } \\
\text { (daños al medio ambiente) } \\
\text { - Sociales (menor calidad } \\
\text { de vida, desplazamiento de } \\
\text { las actividades no turísticas) }\end{array}$ \\
\hline
\end{tabular}

Fuente: elaboración propia, a partir de la metodología de la Comunidad Europea (2004, p. 13) y de las consideraciones de Vera et al. (2013, p. 114) y Telfer y Sharpley (2016, p. 275).

La investigación de campo se realizó mediante observación directa, entrevistas a personas clave y a un grupo de enfoque, se recabó información in situ sobre los aspectos económicos, urbanísticos, ambientales y sociales de la población de Zihuatanejo. Se entrevistó a quienes tenían un cargo de autoridad, con toma de decisiones, o uno de representación de alguna agrupación civil vinculada con el turismo, entre el 2 y 5 de mayo de 2016: tres funcionarios del Ayuntamiento de Zihuatanejo (responsables de turismo, medio ambiente y desarrollo urbano) y uno del gobierno de Guerrero (delegado de Turismo, División Costa Grande); dos miembros de cooperativas (pescadores y lancheros), y un representante de la Asociación de Restauranteros de Zihuatanejo. La entrevista al grupo de enfoque se llevó a cabo el 3 de mayo de 2016, en la unidad Zihuatanejo de la Universidad Autónoma de Guerrero, y estuvo integrado por 25 habitantes de la localidad, entre profesores, alumnos, familiares y amigos, todos con más de cinco años de residencia en el lugar.

\section{Hallazgos sobre la evolución del CVDT de I-Z}

Zihuatanejo se ubica en la bahía del mismo nombre, en la Costa Grande de Guerrero, en el litoral del Pacífico mexicano (ver Figura 1). 


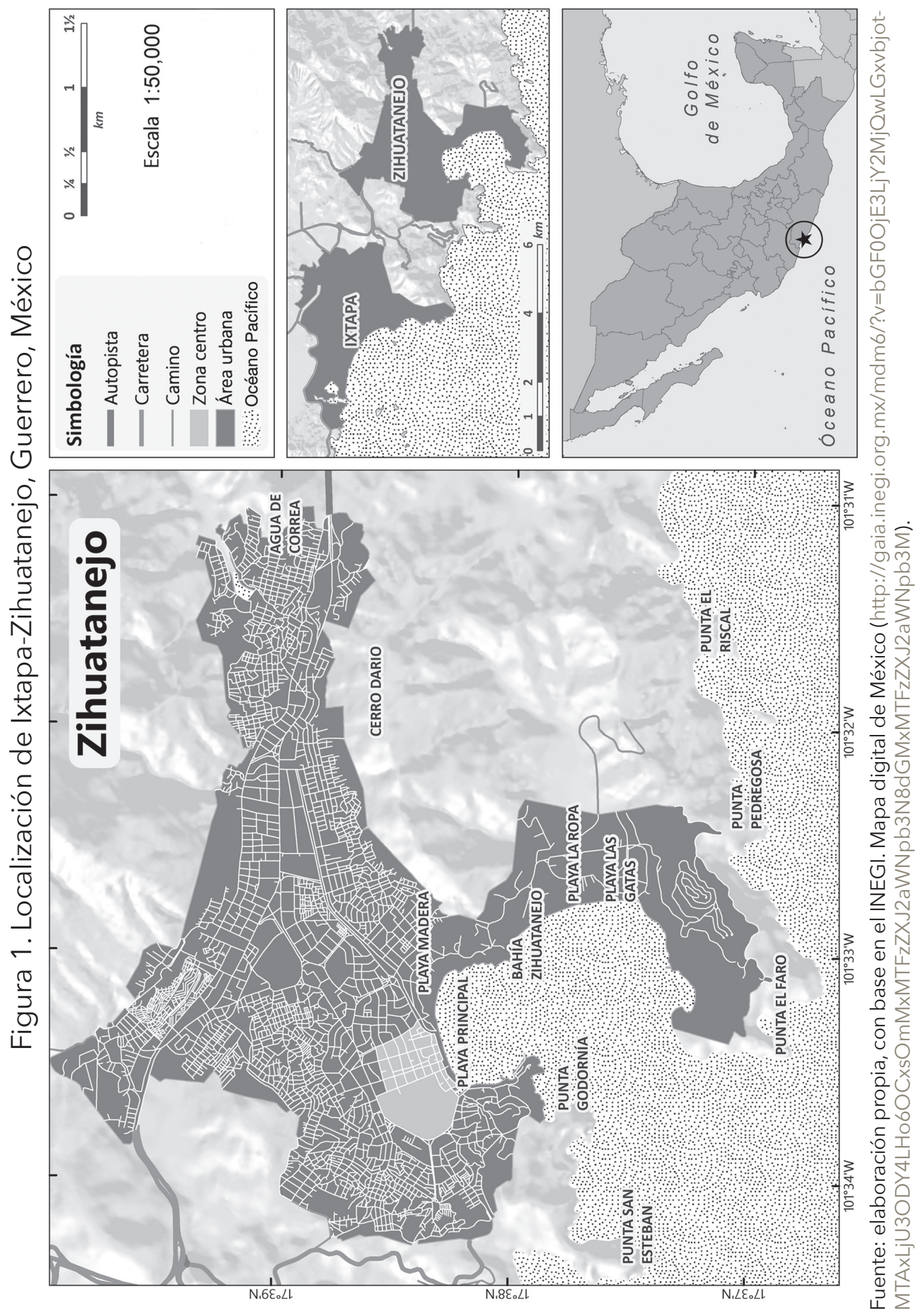


Durante el Virreinato, el sitio fungió como parada de los galeones españoles que arribaban al cercano puerto de Acapulco, así se formó un poblado pesquero que se mantuvo de la producción de cacao, algodón, ganado y copra, a partir del siglo XVI y hasta las primeras décadas del XX (Mombelli, 2010), cuando se trasformó en el ejido de Zihuatanejo (Proceso, 1987).

\section{Etapas: exploración, implicación, desarrollo y estancamiento}

A partir de la década de 1940 la región se empezó a trasformar. El puerto de Acapulco comenzó su desarrollo como centro turístico internacional, dirigido primordialmente al mercado estadounidense, que buscaba lugares de playa alternativos, ante el conflicto bélico que se vivía en Europa por la segunda guerra mundial. En este contexto, por cercanía con Acapulco $(254.1 \mathrm{~km})$, Zihuatanejo empezó a recibir aventureros y visitantes, en los años cincuenta y sesenta, atraídos por lo apacible de su costa y la belleza de sus recursos naturales. Debido a esto, a partir de 1956 se estableció la primera ruta comercial aérea con Ciudad de México, y aparecieron los primeros negocios turísticos de iniciativa local (hoteles Catalina, Irma y Raúl 3 Marías), así como la renta de equipo e instrucción de buceo (El Sur, 2004; Enciclopedia guerrerense, s. f.). Desde entonces, al "pequeño pueblo de pescadores" acudían visitantes que gustaban del buceo, la pesca deportiva y las actividades recreativas y, a partir de 1971, con la llegada del primer barco de procedencia extranjera, se convirtió en un puerto a donde arribaban cruceros.

Cuando el gobierno mexicano decidió implementar la estrategia de creación de los CIP, a principios de la década de 1970, la comunidad se opuso a que el complejo se estableciera en la población asentada, ya que significaba el despojo de sus terrenos, por lo que la empresa Inmobiliaria Fraccionamientos Turísticos, S. A., optó por reubicar el polígono del CIP a $8.5 \mathrm{~km}$ al noroeste (ver Figura 1), y expropiar 400 hectáreas del ejido de Zihuatanejo. De acuerdo con FONATUR, ${ }^{2}$ este CIP fue el primero financiado por el Banco Mundial, cuya superficie era de 2016 ha, se instaló la infraestructura básica, las vialidades, la marina, el campo de golf y el aeropuerto internacional, que comenzó las operaciones en 1974. Para finales de los años setenta y principios de los ochenta, Ixtapa ya contaba con varios hoteles de capital nacional e internacional: Sheraton, Presidente, Dorado Pacífico, Krystal, Club Mediterranée, Westin Brisas Ixtapa, Villa Mexicana y Posada Real, ${ }^{3}$ los que representaron la hotelería corporativa de acuerdo con el modelo turístico masificado de sol y playa, implementado por el gobierno mexicano (SECTUR, 2000). Las décadas de 1980 y 1990 fueron las más "exitosas" del turismo internacional, cuando su comportamiento prácticamente definía el movimiento turístico de la demanda total, con una marcada correlación desde 1986 hasta 2001 (ver Figura 2).

2 FONATUR. Documentos. (https://www.gob.mx/fonatur).

3 www.ixtapayzihuatanejo.com 
Figura 2. Llegadas de turistas al CIP Ixtapa-Zihuatanejo, 1986-2016

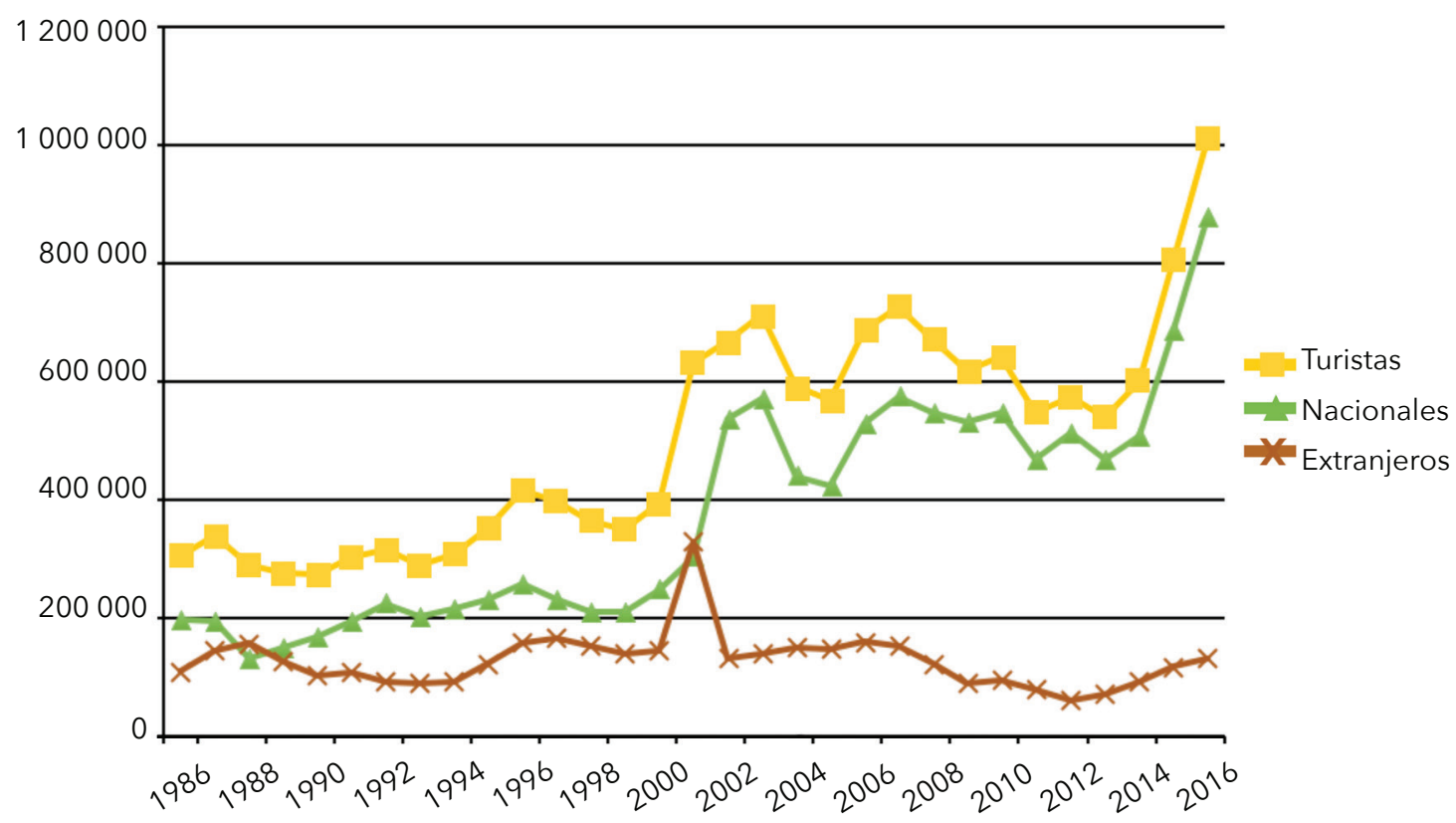

Fuente: elaboración propia, a partir de los datos del Datatur.

Sistema Nacional de Información Estadística y Geográfica de Turismo-SNIEGT. Llegada de turistas.

http://www.datatur.sectur.gob.mx:81/Reportes/Reportes.aspx

De igual forma, la oferta promedio de cuartos se incrementó durante dicho lapso, alcanzó su pico más alto en 2002, cuando se contabilizaron más de 6000 cuartos disponibles (Datatur). Salvo pequeñas oscilaciones, la tendencia tanto de la llegada de turistas como de la oferta de cuartos fue a la alza durante el siglo pasado, sin embargo, a partir del año 2000, el comportamiento se modificó. En 2001, tras un repunte, que duplicó la llegada de turistas extranjeros (TE), al año siguiente hubo una franca caída en este segmento y una tendencia descendente, con una TCMA de 1\%; en 2012 se registró la cifra histórica más baja de la afluencia de TE en 20 años. Por su parte, los turistas nacionales (TN) incrementaron su participación en la demanda, de manera dominante, en 2015 rebasaron los 800 000, y alcanzaron por primera vez el millón. A partir del año 2000 la trayectoria de la demanda la determinan los TN, que registraron una TMCA de 5\% en 20 años (ver Figura 3 y 4). 
Figura 3. Bahía de Zihuatanejo

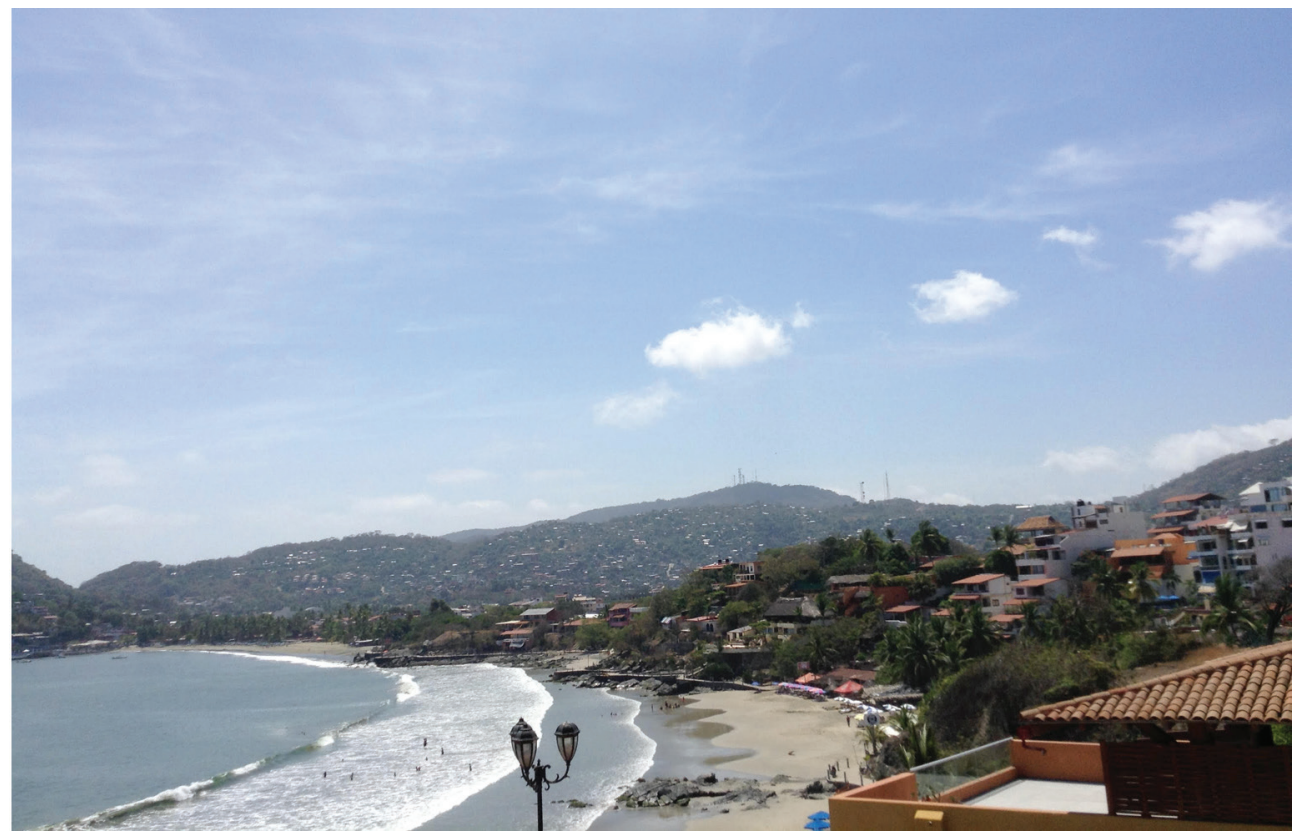

Fuente: fotografía de Maribel Osorio García.

Figura 4. Marina de Ixtapa

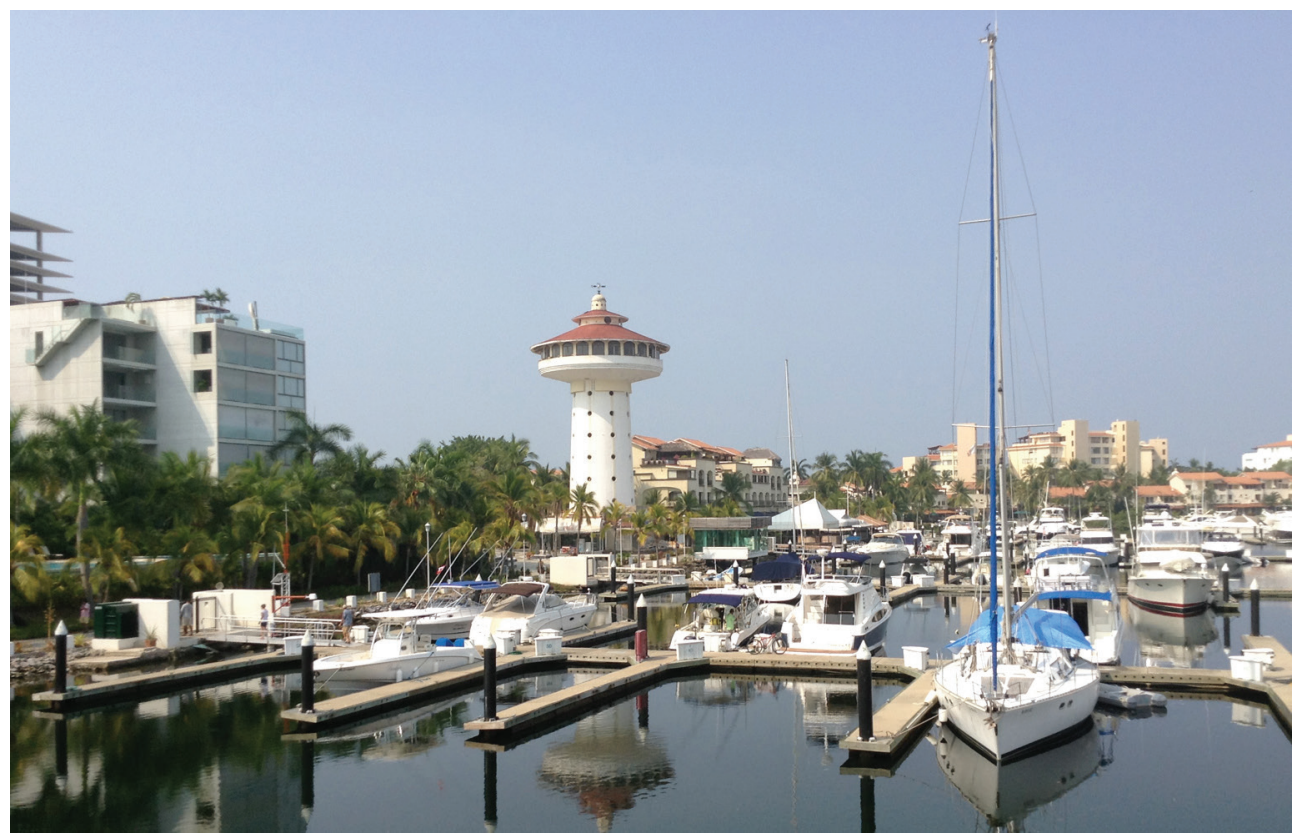

Fuente: fotografía de Maribel Osorio García. 
El cambio de un mercado "equilibradamente mixto" (TE+TN) durante el siglo pasado, a uno de mayoría nacional, en el presente, implicó cambios en las pautas de comportamiento turístico: la ocupación hotelera aumentó de $48.56 \%$, en el año 2000, a 54.37, en 2015, sin embargo la estadía promedio bajó de 4.02, en 1986, a 2.01, en 2016 (ver Figura 5), lo que representa una permanencia de un fin de semana.

Figura 5. Estadía en el CIP Ixtapa-Zihuatanejo, 1986-2016

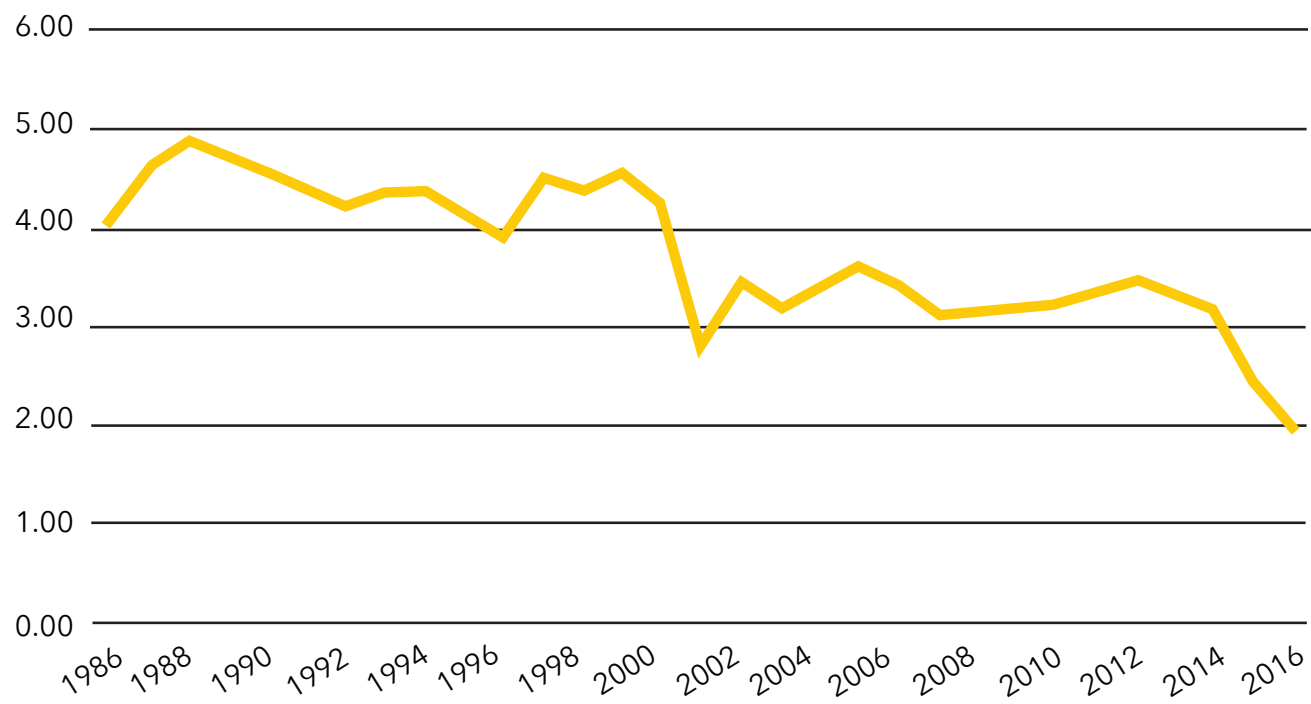

Fuente: Ayuntamiento de Zihuatanejo de Azueta (2016, p. 124); Datatur. Sistema Nacional de Información Estadística y Geográfica de Turismo-SNIEGT Actividad hotelera. http://www.datatur.sectur. gob.mx:81/Reportes/Reportes.aspx

Entonces, se acentúa la estacionalidad, puesto que la movilidad del TN está altamente sujeta a periodos vacacionales y fines de semana. Al corte de 2012, el nivel de satisfacción del turista era de 8.58, por debajo del promedio de 8.72, de los cuatro destinos de playa incluidos en el estudio de desempeño de SECTUR (2012). Cabe señalar que la TCMA de la demanda turística total se fija en un ritmo de $6 \%$, pero la oferta de cuartos no creció a la par, ya que registra una TCMA de 1\%, se estabilizó en el rango de los 5000 cuartos de 2008 en adelante. 


\section{Factores exógenos y endógenos}

¿Qué ocasionó el cambio? De acuerdo con la información obtenida en la investigación, hubo una combinación de factores endógenos y exógenos que alteraron la dinámica e inercia del destino. Entre los externos, se identifican los de tipo político, económico, de competencia y la publicidad negativa:

a) La crisis de seguridad internacional es lo que explica mejor la caída del turismo internacional en I-Z; el que llegaba a este CIP provenía mayoritariamente de Estados Unidos (SECTUR, 2013), por lo que las medidas de seguridad para el tráfico aéreo que adoptó el gobierno estadounidense, ante el ataque terrorista a las Torres Gemelas en Nueva York en 2001, además del miedo colectivo a desplazarse a lugares poco seguros (El País, 2011), provocó la caída del flujo aéreo internacional a México, en general, y a I-Z, en particular.

b) La crisis financiera y económica de 2008, atribuida al colapso del mercado hipotecario y la caída de grandes bancos de inversión, detonó una crisis de producción y empleo en Estados Unidos que repercutió en el ingreso de millones de personas y sus posibilidades de gasto (Zurita, Martínez y Rodríguez, 2009). En consecuencia, en México se produjo una fuerte recesión en el sector de exportaciones y una disminución del flujo de visitantes extranjeros, que provocó una caída general en su afluencia que se prolongó hasta 2011 en el ámbito nacional y hasta 2012 en I-Z.

c) Desde 1990, en el exterior se proyectó la imagen de México como un país violento, y a partir de los años 2000 como la de uno "narcoviolento" (Bergman, 2012; Nexos, 2009). En este contexto, se ha señalado a Guerrero como un estado de los "más violentos", por fungir como territorio en disputa de los cárteles de la droga (Daniel y Zepeda, 2015). En Estados Unidos, el Departamento de Estado emite sistemáticamente alertas para advertir o prohibir a sus ciudadanos viajar a Guerrero (El Economista, 2014; El Universal, 2011, 2016). Para revertir esta imagen, Zihuatanejo obtuvo el certificado de Ciudad Internacional de la Paz en América Latina ante la Organización de las Naciones Unidas, desde 2013, con lo que se logró que las alertas afirmen que I-Z es un lugar seguro para visitar (U.S. Department of State-Bureau of Consular Affairs, 2016), sin que se revierta la minada confianza en su nivel de seguridad (SECTUR, 2012).

d) Pese a las crisis de seguridad y la económica mencionadas, Cancún, Cozumel y Tulum incrementaron su afluencia turística, mantuvieron una imagen de seguridad internacional y ampliaron su oferta de destinos y productos (Riviera Maya), lo que posicionó al estado de Quintana Roo como el más competitivo de México en materia turística (Instituto de Competitividad del Tecnológico de Monterrey, 2012). Este nuevo espacio resultó más atractivo para los TE que antes visitaban los puertos de Guerrero.

Los factores internos son los vinculados con el flujo de visitantes y la calidad del destino: 
a) La mejora de la conectividad nacional aérea y terrestre significó una apertura a nuevos flujos turísticos hacia I-Z. Las aerolíneas de bajo costo (Interjet, Volaris y Viva Aerobus) abrieron rutas a I-Z desde la segunda mitad de los años 2000, aunque este movimiento no se logró sostener en la década siguiente. Sin embargo, en 2005, la construcción de la autopista Siglo XXI produjo el mayor flujo turístico, lo que facilitó el acceso a visitantes de las zonas metropolitanas de Guadalajara, León, Querétaro y Toluca, y abrió el destino a nuevos mercados. Para 2013, 40\% de los visitantes llegaba por vía aérea y 60 por terrestre (Ayuntamiento de Zihuatanejo de Azueta, 2016, p. 126).

b) El mejoramiento en la conectividad terrestre favoreció a los TN de nivel socioeconómico medio y bajo, y atrajo a otros segmentos de las zonas metropolitanas, sobre todo a trabajadores sindicalizados y jubilados, incentivados por convenios impulsados por las autoridades locales y estatales con instituciones públicas federales de carácter social, como el Instituto de Seguridad y Servicios Sociales de los Trabajadores del Estado, lo que fomentó un "turismo social" de bajo precio, que se desplaza de forma masiva y estacional a Zihuatanejo. La conectividad terrestre también incentivó al turismo residencial de alto nivel, localizado en Ixtapa. De acuerdo con la información contenida en el Plan Director de Desarrollo Urbano de Zihuatanejo-Ixtapa, ha sido mayor la superficie vendida para uso residencial que para el hotelero: “[...] este destino, que de origen se enfocó en la oferta hotelera, se ha ido consolidando como un lugar de segundas residencias y tiempo compartido" (Ayuntamiento de Zihuatanejo de Azueta, 2016, p. 123).

c) La hotelería de alto nivel de Ixtapa tuvo que bajar el precio, para captar los segmentos nacionales de mejores ingresos, y aumentar sus índices de ocupación, además implementó los servicios “todo incluido" y "tiempos compartidos”, para concentrar la captación del gasto. En los últimos años, este tipo de hotelería ha incursionado en el turismo de romance, de bodas y lésbico, gay, bisexual y transgénero, segmentos atractivos por su alto gasto. Por otra parte, los visitantes de ingresos medios y bajos generaron un turismo popular que se movilizó a Zihuatanejo, para minimizar los costos del viaje y abrir la oportunidad para que proliferaran alojamientos informales con servicio de baja calidad. Dichos establecimientos han representado un problema para las autoridades municipales, ya que no cubren el registro oficial correspondiente y, por tanto, no hay garantía de que ofrezcan los estándares mínimos de higiene y servicio.

d) El deterioro ambiental del producto turístico de I-Z produjo un cambio, de un segmento de turistas de alto nivel socioeconómico a uno masivo de menor exigencia. A partir de 2003, el gobierno federal estableció el Programa de Playas Limpias, que implementó un monitoreo bacteriológico de la calidad del agua, a través de la norma mexicana NMX-AA-120-SCFI-2006, que regula los requisitos y especificaciones de sustentabilidad de las playas. ${ }^{4} \mathrm{El}$ gobierno de Guerrero incorporó a I-Z al programa, y obtuvo su primera certificación

4 CONAGUA. Programa Playas Limpias, Agua y Ambiente Seguros (Proplayas). (https://www.gob.mx/ conagua/acciones-y-programas/programa-playas-limpias-agua-y-ambiente-seguros-proplayas). 
nacional en la playa El Palmar de Ixtapa, en 2010, y en 2013 la internacional Blue Flag, pero el resto de las playas no lo lograron. Para 2014, la Playa Principal de Zihuatanejo fue calificada como la más contaminada de México (Franco, 2014), además de La Madera, Las Gatas y La Ropa y una de Ixtapa (Varadero) se destacaron por su alto grado de contaminación.

Como se puede apreciar, la evolución de I-Z lejos de dar muestras de estar en una etapa de desarrollo, de acuerdo con el modelo de CVDT, presenta varios signos de declive: reducción de la estadía promedio, concentración estacional de flujos, cambios en la composición de visitantes, disminución tanto de la calidad de los turistas como del producto turístico, y daños al medio ambiente. Los cambios sufridos por el destino han fomentado el crecimiento de la comunidad de Zihuatanejo, y una sinergia centrada en el turismo doméstico, como una alternativa a la estrategia fallida de enclave, propiciada por el modelo del CIP.

\section{Cambios y problemáticas en I-Z}

El mayor cambio que produjo la creación del CIP se reflejó claramente en el crecimiento de la población, ya que generó un proceso de terciarización económica y de urbanización acelerada. La construcción de todo el complejo requirió mano de obra para la edificación de los inmuebles (Mota, 1995) y la prestación de los servicios, requerimientos que produjeron inmigración procedente del entorno y de Acapulco, lo que ocasionó que los habitantes, la población ocupada y las viviendas crecieran a un ritmo inusitado.

Durante los años ochenta, la población creció a un ritmo de $9.4 \%$, aumentó 37 615 personas, y se duplicó la de base, de 1980. Aunque el crecimiento del personal ocupado fue menor (7.1\%), en la década de 1990 alcanzó su récord histórico, cuando 11 mil personas se sumaron al sector terciario. La vivienda fue el factor que creció más rápido, alcanzó 11.5\%, fenómeno que significó la aparición de 9 179 viviendas en 10 años. Durante la década de 1990 hubo una desaceleración en el crecimiento, aunque la tasa del personal ocupado se mantuvo cerca de la cifra anterior, que colocó a 71\% del personal en el sector terciario. Los altibajos en la llegada de turistas, entre el año 2000 y 2010, ocasionaron una baja en las tasas de crecimiento de los tres indicadores mencionados. No obstante, se sumaron 13233 personas a la población ocupada y otras 9987 viviendas, prácticamente la misma cantidad del decenio anterior (ver Tabla 3).

Los datos económicos censales de la primera década del presente siglo proporcionan un panorama complementario, pero a la vez revelador. De acuerdo con las cifras oficiales del INEGI, ${ }^{5}$ los sectores de comercio al por menor (46), al por mayor (43) y de alojamiento y alimentos (72) concentraban 72 y $68 \%$ del total de unidades económicas para 2003 y 2008, respectivamente. ${ }^{6}$ Sin embargo, destaca la posición minoritaria que estos tres sectores tienen con respecto al

5 Censos Económicos. (http://www.beta.inegi.org.mx/datos/?init=2).

6 El sector comercio, tanto al por menor como al por mayor, integran la sinergia turística del destino, por lo que se asumen como parte de las actividades económicas encadenadas a él. 
22, que es el de electricidad, agua y suministro de gas por ductos al consumidor final, el cual concentró 80 y 79\% del valor agregado total para 2003 y 2008 (ver Tabla 4).

Tabla 3. Habitantes, población ocupada y vivienda en el municipio de Zihuatanejo de Azueta, 1970-2010

\begin{tabular}{|c|c|c|c|c|r|r|c|}
\hline \multirow{2}{*}{ Año } & \multicolumn{2}{|c|}{ Habitantes } & \multicolumn{2}{c|}{ Población ocupada } & \multicolumn{2}{c|}{ Vivienda } \\
\cline { 2 - 8 } & Absoluto & TCMA & Absoluto & TCMA & $\begin{array}{c}\text { Sector } \\
\text { terciario (\%) }\end{array}$ & Absoluto & TCMA \\
\hline 1970 & 17873 & Sin datos & Sin datos & Sin datos & Sin datos & Sin datos & Sin datos \\
\hline 1980 & 25751 & 3.7 & 10138 & Sin datos & 20 & 4635 & Sin datos \\
\hline 1990 & 63366 & 9.4 & 20120 & 7.1 & 65 & 13814 & 11.5 \\
\hline 2000 & 95548 & 4 & 35543 & 5.9 & 71 & 22597 & 5 \\
\hline 2010 & 118487 & 2 & 48776 & 3.2 & 74.5 & 32584 & 4 \\
\hline
\end{tabular}

TCMA - Tasa de crecimiento media anual.

Fuente: elaboración propia, a partir de datos de INEGI. Censos y Conteos de Población y Vivienda (http://www.beta.inegi.org.mx/datos/?init=2).

Tabla 4. Indicadores económicos del municipio de Zihuatanejo de Azueta, 2003 y 2008

\begin{tabular}{|c|r|r|r|r|r|r|r|r|}
\hline \multirow{2}{*}{ Sector } & \multicolumn{2}{|c|}{$\begin{array}{c}\text { Unidades } \\
\text { económicas }\end{array}$} & \multicolumn{2}{c|}{$\begin{array}{c}\text { Personal } \\
\text { ocupado }\end{array}$} & \multicolumn{2}{c|}{$\begin{array}{c}\text { Remuneraciones } \\
\text { (miles de pesos) }\end{array}$} & \multicolumn{2}{c|}{$\begin{array}{c}\text { Valor agregado } \\
\text { (miles de pesos) }\end{array}$} \\
\cline { 2 - 10 } & 2003 & 2008 & 2003 & 2008 & 2003 & 2008 & 2003 & 2008 \\
\hline $\begin{array}{c}\text { Total } \\
\text { municipio }\end{array}$ & 4527 & 6172 & 22492 & 29718 & 1065007 & 1241050 & 8940548 & 9921087 \\
\hline 22 & 0 & 0 & 2406 & 1892 & 512856 & 471847 & 7107763 & 7821388 \\
\hline 43 & 77 & 113 & 926 & 1102 & 64463 & 73254 & 259615 & 211984 \\
\hline 46 & 2457 & 2977 & 5786 & 8165 & 69826 & 117808 & 355511 & 387668 \\
\hline 72 & 711 & 1110 & 6135 & 8601 & 155182 & 237003 & 467912 & 768991 \\
\hline
\end{tabular}

Fuente: elaboración propia, a partir de los datos de INEGI. Censos económicos.

(http://www.beta.inegi.org.mx/datos/?init=2). 
En este sentido, para 2008, el turismo del municipio (medido por el sector 72) aportaba $29 \%$ de personal ocupado, 19 de las remuneraciones y 8 del valor agregado. Visto así, la importancia del turismo radica en su capacidad de ocupar personal, aunque su promedio de remuneración por persona ocupada ( $\$ 27.5 \mathrm{mil}$ al año) se encuentra por debajo de la media municipal ( $\$ 41.7 \mathrm{mil})$. De acuerdo con las cifras anotadas, una persona ocupada en el sector 72 ganaba, en promedio, \$70.26 diarios en 2003 (6.7 dólares) y \$76.53 en 2008 (7 dólares). ${ }^{7}$

No obstante que las cifras son bajas, el ingreso en el municipio de Zihuatanejo mejoró paulatinamente, para 1970, 83.55\% de la población obtenía hasta un salario mínimo y 57.65\% ganaba de menos uno hasta tres, en 1990 (Mota, 1995, p. 115). Para 2010 se estimó que $60.8 \%$ de la población ocupada en el subsector de hoteles y restaurantes ganaba entre uno y tres salarios mínimos (Ayuntamiento de Zihuatanejo de Azueta, 2016). Cabe señalar, sin embargo, que la condición del empleo hotelero de cadena ha manifestado la misma problemática identificada en otros centros turísticos periféricos (Cañada, 2015): eventual, parcial y subcontratado, como lo constató Brenner (1999) para el caso de I-Z.

Los cambios físicos generados por el proceso de urbanización acelerado se detonan a partir de la política e inversión públicas emprendidas por el gobierno federal, al crear una "zona turística" en un asentamiento alejado de Zihuatanejo (ver Figura 1), cuya expropiación de suelo, construcción y mantenimiento corrió a cargo del erario federal. En el centro de Zihuatanejo también se expropiaron tierras ejidales, en un polígono que abarca 2230.04 hectáreas (Ayuntamiento de Zihuatanejo de Azueta, 2016). Así fue como FONATUR se quedó como operador y gestor de Ixtapa, mientras que Zihuatanejo quedó a cargo del Fideicomiso Bahía de Zihuatanejo. Dichos organismos se encargaron de la indemnización de los terrenos expropiados - que aún no se han liquidado totalmente (La Plaza, 2017)-, lo que convirtió al ordenamiento urbano en una tarea complicada. Con base en lo planteado en el Plan Director de Desarrollo Urbano de Zihuatanejo-Ixtapa, Guerrero 2015-2030, se puede aducir que son dos los procesos que conforman la problemática urbana de Zihuatanejo: la turistificación del suelo y la pauperización de la periferia. En relación con el primero, en la zona centro se concentraron los servicios turísticos de carácter popular, y se tornó en un espacio comercial anárquico por la mezcla de usos, la sobreocupación del suelo y el conflicto vial incontrolable en sus estrechas calles. Por otro lado, en el litoral de la bahía la privatización ha sido paulatina por parte de empresas y residencias turísticas, para conseguir la rentabilidad del escenario natural. En la zona centro y en el litoral, la disposición del suelo pronto se volvió limitada y costosa para la población local, por lo que la necesidad urgente de viviendas, ante el crecimiento inusitado en las décadas de 1990 y 2000, derivó en la formación de colonias que remontaron la serranía, y se fueron extendiendo a lo largo de las carreteras, manglares y esteros. El área urbana creció en 1070 ha, entre 1995 y 2012, a un ritmo de $2.4 \%$ anual, de manera anárquica, precaria e irregular (Ayuntamiento de Zihuatanejo de Azueta, 2016).

La pauperización de la periferia se debió a la proliferación de asentamientos humanos irregulares $(\mathrm{AHI})$ en zonas no aptas para el desarrollo urbano, derivado

7 La conversión peso-dólar está calculada al 30 de junio de 2003 y 2008 (http://www.idconline.com. $m \times /)$. 
de la tenencia irregular de la tierra, así como de la preminencia del uso turístico del suelo. Estos asentamientos carecen de servicios e infraestructura básica, y no tienen los estándares mínimos de calidad en las viviendas. Sus habitantes se encuentran en situación de pobreza, y están sujetos a desalojos y reubicaciones forzadas. En 2005 se identificaron 42 AHI, y en 2016 se censaron otros 26. La problemática se torna crítica al reconocer que "[...] el área de estudio carece de zonas aptas para el crecimiento urbano, particularmente de suelo para vivienda destinado a personas de escasos recursos" (Ayuntamiento de Zihuatanejo, 2016, p. 138). Las condiciones urbanas en I-Z son muy dispares; por una parte existen lotes destinados a usos turísticos, controlados por el FONATUR ${ }^{8}$ y el Fideicomiso Bahía de Zihuatanejo, para la venta de terrenos del CIP y, por otra, no hay suelo disponible para el crecimiento de la población, sobre todo para la más vulnerable. El enclave turístico, a pesar de su origen planificado con miras al desarrollo, fraccionó el espacio y provocó discontinuidad del paisaje y ruptura en su dinámica, además produjo alta segregación socioeconómica y acentuó la desigualdad microregional (Dávila, 2014; Núñez y López, 2016; SECTUR, 2000; Telfer y Sharpley, 2016) que aumenta conforme transcurre el tiempo.

La urbanización acelerada activó el deterioro ambiental, que impactó a I-Z. El crecimiento desbordado de la vivienda derivó en una sobrecarga en el consumo de agua; para 2015 se calculó que 34\% de las colonias de Zihuatanejo recibían agua potable a diario (Ayuntamiento de Zihuatanejo de Azueta, 2016). El problema no solo se refiere al agua potable, sino a la gestión de las aguas negras, ya que las plantas de tratamiento presentan problemas de capacidad y separación de sólidos, por lo que el agua tratada es de baja calidad y mayormente descargada al mar, lo que contamina la franja costera. Por consiguiente, las condiciones urbana y ambiental han sido desfavorables para la calidad de vida de la población, no obstante, en los indicadores sociales de Zihuatanejo su repercusión parece moderada (ver Tabla 5).

Tabla 5. Indicadores sociales del municipio de Zihuatanejo

\begin{tabular}{|c|c|}
\hline Índice de desarrollo humano (IDH) & 0.723 (nivel medio) \\
\hline Índice de marginación (IM) & -1.0292 (grado bajo) \\
\hline Índice de intensidad migratoria & 2.1107 (grado bajo) \\
\hline $\begin{array}{c}\text { Población con ingreso inferior } \\
\text { a la línea de bienestar }\end{array}$ & $58 \%$ \\
\hline Población en situación de pobreza & $53.6 \%$ \\
\hline Población vulnerable por carencias sociales & $30.6 \%$ \\
\hline Carencia por acceso a servicios de salud & 63.1 (el doble de la media nacional) \\
\hline Carencia por calidad y espacios de la vivienda & 38.3 (el doble de la media nacional) \\
\hline
\end{tabular}

Fuente: elaboración propia, con información obtenida del Ayuntamiento de Zihuatanejo de Azueta (2016).

8 FONATUR. Acciones y programas. (http://www.fonatur.gob.mx/es/terrenos/index.asp). 
Tabla 6. Síntesis de los factores exógenos y endógenos causantes del declive en I-Z

\begin{tabular}{|c|c|}
\hline Exógenos & $\begin{array}{l}\text { - Crisis de seguridad por el atentado terrorista } \\
\text { en Estados Unidos en 2001, que produjo } \\
\text { una disminución de visitantes a México } \\
\text { - Crisis inmobiliaria y financiera en Estados Unidos, en 2008, } \\
\text { que disminuyó los visitantes extranjeros a México } \\
\text { - Posicionamiento de los destinos del Caribe en México, } \\
\text { como los más atractivos y seguros } \\
\text { - Publicidad negativa por las alertas del gobierno } \\
\text { estadounidense a sus ciudadanos para no visitar } \\
\text { el estado de Guerrero, declarado como el más inseguro } \\
\text { y violento de México }\end{array}$ \\
\hline Endógenos & Datos \\
\hline $\begin{array}{l}\text { Reducción } \\
\text { del flujo de } \\
\text { visitantes }\end{array}$ & $\begin{array}{l}\text { - Menos afluencia de turistas extranjeros, segmento al } \\
\text { que estuvo dirigida la creación del CIP } \\
\text { - La estadía promedio disminuyó de } 4 \text { a } 2 \text { noches en } 30 \text { años } \\
\text { - El flujo turístico aumentó su estacionalidad, se concentró } \\
\text { en los fines de semana y los periodos vacacionales }\end{array}$ \\
\hline $\begin{array}{c}\text { Disminución de } \\
\text { los elementos que } \\
\text { definían la calidad } \\
\text { del destino }\end{array}$ & $\begin{array}{l}\text { - Disminución del segmento internacional y sustitución } \\
\text { por los domésticos, de niveles socioeconómicos } \\
\text { medio y bajo } \\
\text { - Crecimiento del turismo popular } \\
\text { - Baja de precio en los hoteles y proliferación } \\
\text { de alojamiento informal } \\
\text { - Fuerte contaminación ambiental de las playas, } \\
\text { principal recurso turístico }\end{array}$ \\
\hline $\begin{array}{l}\text { Dificultades } \\
\text { para garantizar un } \\
\text { turismo sostenible }\end{array}$ & $\begin{array}{l}\text { - Empleo eventual y subcontratado en el sector. Promedio } \\
\text { - Ce remuneración por debajo de la media municipal } \\
\text { desorden urbano y segregación } \\
\text { - Asentamientos irregulares y pauperización de la periferia } \\
\text { - Deterioro ambiental por gestión deficiente } \\
\text { de aguas negras y sobrecarga en el consumo de agua } \\
\text { - Dos tercios de la población en rezago de dotación } \\
\text { de agua y un tercio de ella sin calidad en la vivienda } \\
\text { - Vulnerabilidad de la mitad de la población } \\
\text { por situación de pobreza }\end{array}$ \\
\hline
\end{tabular}

Fuente: elaboración propia, con información obtenida en la investigación. 
Los indicadores del IDH y el de IM dan cuenta de una situación más propicia que la del contexto de Guerrero y del país, sin embargo, la condición del ingreso y la pobreza mantiene a la mitad de la población en rezago y vulnerable en cuanto al acceso a servicios de salud y calidad de la vivienda.

Entonces, la implantación del modelo turístico de enclave, como estrategia de desarrollo en Zihuatanejo, generó expectativas en el contexto regional que provocó inmigración y un alto crecimiento de la población, de la ocupación y de la vivienda durante la década de 1990, lo que disparó el crecimiento urbano y los requerimientos de infraestructura, servicios básicos y condiciones de bienestar. Al caer el comportamiento del mercado turístico internacional, al inicio del nuevo siglo, y sustituirse por mercados nacionales de nivel socioeconómico menor o de derrama escasa, se ralentizó el crecimiento. Aunque los salarios turísticos y comerciales promedio (sector 46) no cayeron en el trascurso de la primera década del presente siglo, fueron incapaces de cubrir rezagos importantes de bienestar y de superación de la pobreza para la mitad de la población. En la Tabla 6 se sintetizan los factores que originan el declive en la evolución turística de I-Z.

\section{Conclusiones}

De acuerdo con lo establecido en el planteamiento teórico-metodológico sobre las líneas de análisis que guiaron esta investigación, los hallazgos obtenidos sobre la evolución de I-Z como destino turístico muestran fehacientemente un comportamiento de declive, evidenciado por el conjunto de signos negativos que presenta la demanda, la oferta y los cambios estudiados. El ascenso aparente que desvela la llegada de turistas, y que clasificaría al CIP en una etapa de "desarrollo", queda desenmascarado al conocer la recomposición de los flujos turísticos y el comportamiento de los indicadores de la estadía, la estacionalidad y la ocupación.

En efecto, se observa una simultaneidad de indicadores de etapas distintas, tal como lo afirmó Hovinen (2002), y coexisten los de crecimiento (la llegada de turistas y la población ocupada en el sector turístico), de estancamiento (la oferta de cuartos disponibles y las remuneraciones del personal) y de declive (la estadía y los precios), que proporcionan una imagen ambivalente de su estadio ofuscando una visión sobre su realidad, sin embargo, el diagnóstico de declive que se sostiene aquí se cifra en reconocer la recomposición de los flujos turísticos, la pérdida de calidad del destino y las dificultades para garantizar un turismo sostenible, de acuerdo con la metodología de la Comisión Europea. De hecho, no se podría afirmar estrictamente que I-Z alcanzó una etapa de consolidación, puesto que el turismo no llegó a convertirse en el sector económico dominante del municipio.

Desde la perspectiva de esta investigación, I-Z tuvo un ciclo de vida frustrado que detuvo su etapa de desarrollo planificado como destino turístico internacional en 2001, y a partir de entonces tuvo que empezar una recomposición de su dinámica turística improvisando acciones que le permitieran afrontar su nueva situación de destino turístico nacional. Este cambio drástico, provocado básicamente por los factores exógenos, ha dado lugar a un ciclo de vida desordenado y 
descontrolado, sin que los gestores y prestadores de servicios renuncien a su pasado turístico internacional. Cabe señalar que el repunte del TE se avizora como algo muy difícil de lograr, dado que hay factores que siguen presentes como la publicidad negativa, la inseguridad del entorno estatal y el posicionamiento de los destinos del Caribe, y que se proyectan sin cambio para el corto y mediano plazo.

Aunque la capacidad de carga del destino nunca fue rebasada con respecto a la cantidad de población, los cambios generaron problemáticas urbanas, ambientales y sociales, como los asentamientos irregulares, la contaminación del mar y la falta de calidad de la vivienda. Sin embargo, la derrama económica derivada del turismo ha significado un gran beneficio en términos de la población ocupada y sus remuneraciones, dada la condición de marginación del contexto estatal en el que se asienta, por lo que los habitantes valoran sobremanera la actividad turística: "teniendo turismo, todo el mundo está contento" (entrevista con el delegado estatal de Turismo, 4 de mayo de 2016). Entonces, el caso de estudio demuestra que en un destino en declive no necesariamente existe una correlación entre beneficios económicos bajos y muchos problemas ambientales y socioculturales, puesto que en I-Z a los beneficios económicos que provee el turismo se les da gran valor, a pesar de los problemas urbanos, ambientales y sociales que ahora enfrenta.

En prospectiva, se puede decir que hay una probabilidad elevada de que el destino se consolide como uno de los favoritos de playa del turismo doméstico en México, dada su cercanía con mercados nacionales importantes, su precio competitivo y su imagen como una ciudad "pacífica", en contraste con la violencia del puerto de Acapulco, su vecino. De lograr la mejora de la calidad sustentable de las playas, se podría renovar el perfil del visitante nacional, y acercar a segmentos de mayor gasto turístico y con conciencia ambiental.

De hecho, para contrarrestar los signos de declive enunciados aquí, y alcanzar una prospectiva mejor, se podría establecer una estrategia integral de intervención con dos vectores: renovar la calidad del destino y mejorar la calidad de vida de la población. En ambos casos, la atención al manejo ambiental de los residuos sólidos y el tratamiento de aguas negras es primordial, puesto que se requiere recuperar la calidad de las playas y resolver la contaminación que perjudica a los recursos marinos, a la población y a la atracción de los turistas. En la renovación de la calidad del destino es importante la regulación de los servicios de alojamiento, para garantizar que sean satisfactorios y evitar la competencia desleal.

Para mejorar la calidad de vida de la población es imperativo resolver el ordenamiento urbano, implementar programas sociales de mejora de vivienda y otorgar infraestructura y servicios básicos requeridos en la periferia (Vera y Baños, 2010), todo con procesos de planeación y gestión participativa (López, 2011). También valdría la pena reflexionar sobre una política de contención de crecimiento urbano y desincentivar la inmigración, para cubrir los requerimientos sociales de la población actual, y romper la sinergia del aumento demográfico causada por la inmigración laboral de décadas pasadas. 


\section{Referencias}

Agarwal, S. (2002). Restructuring seaside tourism: The resort lifecycle. Annals of Tourism Research, 29(1), 25-55. doi: 10.1016/S0160-7383 (01) 00002-0

Aguiló, E., Alegre, J. y Sard, M. (2005). The persistence of the sun and sand tourism model. Tourism Management, 26(2), 219-231. doi: 10.1016/j.tourman.2003.11.004

Ap, J. (1992). Resident's perceptions on tourism impacts. Annals of Tourism Research, 19(4), 665-690. doi: 10.1016/0160-7383(92)90060-3

Ayuntamiento de Zihuatanejo de Azueta. (2014). Plan Municipal de Desarrollo 2015-2018. Recuperado de http://doczz.es/doc/5068302/plan-municipal-de-desarrollo---h.-ayuntamiento-de-zihuata

Ayuntamiento de Zihuatanejo de Azueta. (2016). Plan Director de Desarrollo Urbano de Zihuatanejo-Ixtapa, Guerrero, 2015-2030. Recuperado de https: / / static1.squarespace.com/static/575da24df8baf38dc65313b0/t/5771a996b3db2bc279252781/1467066840959/Documento+0+PDDUZI+1530.pdf

Banco de México. (2017). Sistema de Información Económica. Viajeros internacionales 2017. Recuperado de http://www.banxico.org.mx/Sielnternet/ consultarDirectoriolnternetAction.do?accion=consultarCuadroAnalitico\&id Cuadro=CA198\&sector $=1 \&$ locale $=$ es

Bergman, M. (2012). La violencia en México: algunas aproximaciones académicas. Desacatos, 40, 65-76. doi: 10.29340/40.256

Bravo Luján, L. (1994). La política de impulso turístico en México. Ixtapa-Zihuatanejo como polo de desarrollo turístico (tesis de maestría). Recuperada de http://oreon.dgbiblio.unam.mx/F/SHUQLEVMQUNSNPSKMHICF48K7I32KTJ2VG9TGLSN86H62LK4JQ-21759?func=full-set-set\&set_number=017255\& set_entry=000001\&format $=999$

Brenner, L. (1999). Modelo para la evaluación de la "sustentabilidad" del turismo en México con base en el ejemplo de Ixtapa-Zihuatanejo. Investigaciones Geográficas, 39, 139-158. doi: 10.14350/rig.59089

Bianchi, R. (1994). Tourism development and resort dynamics: An alternative approach. En C. P. Cooper y A. Lockwood (eds.), Progress in tourism, recreation and hospitality management (pp. 181-193). Chichester: John Wiley \& Sons Ltd.

Butler, R. W. (1980). The concept of a tourist area cycle of evolution: Implications for management of resources. Canadian Geographer/Le Géographe canadien 24(1), 5-12. doi: 10.1111/j.1541-0064.1980.tb00970.x

Butler, R. W. (2004). The tourism area life cycle in the twenty-first century. En A. Lew, M. Hall y A. Williams, A companion to tourism (pp. 159-170). Massachusetts: Blackwell Publishing.

Butler, R. W. (2006). The origins of the tourism area life cycle. En R. W. Butler, The tourism area life cycle. Volume 1. Applications and modifications (pp. 13-26). Clevedon: Channelview Publications.

Butler, R. W. (2011). Tourism area life cycle. Contemporary Tourism Reviews. Recuperado de http://www.goodfellowpublishers.com/free_files/fileTALC. pdf 
Butler, R. W. (2012). Mature tourist destinations: Can we recapture and retain the magic? En J. Vera e I. Sánchez, Renovación y restructuración de destinos turísticos en áreas costeras. Marco de análisis, procesos, instrumentos y realidades (pp. 19-36). Valencia: Universidad de Valencia.

Cañada, E. (2015). Los que limpian los hoteles. Historias ocultas de precariedad laboral. Barcelona: Icaria.

Christaller, W. (1964). Some considerations of tourism location in Europe: The peripheral regions-underdeveloped countries-recreation areas. Papers in $R e$ gional Science, 12 (1), 95-105.

Comisión Europea. (2004). Sistema de Alerta Rápida para la Detección de Destinos Turísticos en Declive y Mejores Prácticas de Prevención. Recuperado de https://asesoresenturismoperu.files.wordpress.com/2016/05/188-sistema-para-la-deteccion-de-destinos-turisticos-en-declive.pdf

Daniel Rosen, J. D. y Zepeda Martínez, R. (2015). La guerra contra el narcotráfico en México: una guerra perdida, Reflexiones, 94 (1), 153-168. Recuperado de http: / / www.redalyc.org/pdf/729/72941346011.pdf

Dávila López, A. (2014). Centros integralmente planeados (CIPS) en México: las piezas del proyecto turístico de FONATUR. Recuperado de http://upcommons.upc.edu/handle/2099/15985

Deery, M., Jago, L. y Fredline, L. (2012). Rethinking social impacts of tourism research: A new research agenda. Tourism Management, 33(1), 64-73. doi: 10.1016/j.tourman.2011.01.026

Deverdum Reyna, M. G., Osorio Gacía, M. e Iracheta Cenecorta, A. (2016). El turismo residencial en Valle de Bravo, México. Una interpretación de su ciclo de vida. Investigaciones Turísticas, 11, 30-51. doi: 10.14198/INTURI2016.11.02

Diedrich, A. y García-Buades, E. (2009). Local perceptions of tourism as indicators of destination decline. Tourism Management, 30, 512-521. doi: 10.1016/j. tourman.2008.10.009

El Economista. (29 de diciembre de 2014). Pide EU no visitar Guerrero y Estado de México. Recuperado de http://eleconomista.com.mx/sociedad/2014/12/29/ pide-eu-no-visitar-guerrero-estado-mexico

El País. (9 de marzo de 2011). 11 de septiembre, el día que el mundo cambió para siempre. Recuperado de http://www.elpais.com.co/mundo/11-de-septiembre-el-dia-que-el-cambio-para-siempre.html

El Sur. (14 de febrero de 2004). Periódico de Guerrero reconoce el Ayuntamiento de Zihuatanejo al piloto del primer vuelo comercial. Recuperado de http://suracapulco.mx/1/reconoce-el-ayuntamiento-de-zihuatanejo-al-piloto-del-primer-vuelo-comercial-20; IxyZih. Ixtapa y Zihuatanejo. Divulgación. https: / /ixtapayzihuatanejo.com

El Universal. (2 de agosto de 2011). Cronología alertas de viaje emitidas por EU. Recuperado de http://archivo.eluniversal.com.mx/notas/828849.html

El Universal. (15 de abril de 2016). Renueva EU alerta de viaje a México; prohíbe visitar Guerrero. Recuperado de http://www.eluniversal.com.mx/articulo/ nacion/seguridad/2016/04/15/renueva-eu-alerta-de-viaje-mexico-prohibe-visitar-guerrero

Enciclopedia guerrerense. (s.f.). Recuperado de http://www.enciclopediagro. org 
Franco, L. (1 de julio de 2014). Playa principal de Zihuatanejo, la más contaminada de México. La Crónica. Recuperado de http://www.cronica.com.mx/ notas/2014/842352.html

García-Ayllon, S. (2015). Geographic Information System (GIS). Analysis of impacts in the tourism area life cycle (TALC) of a Mediterranean Resort. International Journal of Tourism Research, 18, 186-196. doi: 10.1002/jtr.2046

García Henche, B., Reinares Lara, E. y Armelini, G. (2012). Ciclo de vida de los destinos turísticos y estrategias de comunicación: los casos de España y Chile. Revista Internacional de Investigación en Comunicación aDResearch ESIC 7(7), 76-93. doi: 10.7263/ADR.RSC.007.05

Garay, L. y Cánoves V., G. (2011). Life cycles, stages and tourism history. The Catalonia (Spain) experience, Annals of Tourism Research, 38(2), 651-671. doi: $10.1016 / j$.annals.2010.12.006

Getz, D. (1992). Tourism planning and destination life-cycle. Annals of Tourism Research, 19(4), 757-770. doi: 10.1080/10349952.1998.11876689

Harrison, D. (1995). Development of tourism in Swaziland. Annals of Tourism Research, 22(1), 135-156. doi: 10.1016/0160-7383(94)00051-S

Haywood, K. M. (1986). Can the tourist area life-cycle be made operational? Tourism Management, 7(3), 154-167. doi: 10.1016/0261-5177(86)90002-6

Hernández-Lobato, L., Solís-Radilla, M., Moliner-Tena, M. A., y Sánchez-García, J. (2006). Tourism destination image, satisfaction and loyalty. A study in Ixtapa-Zihuatanejo, Mexico. Tourism Geographies, 8(4), 343-358. doi: 10.1080/14616680600922039

Hiernaux Nicolas, D. (1985). 10 años de los polos de desarrollo turístico en México: experiencias y perspectivas. Recuperado de https://www.academia. edu/25374789/10_a\%C3\%B10s_de_polos_de_desarrollo_tur\%C3\%ADstico_ en_M\%C3\%A9xico_experiencias_y_perspectivas

Hovinen, G. R. (2002). Revisiting the destination lifecycle model. Annals of Tourism Research, 29(1), 209-230. doi: 10.1016/S0160-7383(01)00036-6

Instituto de Competitividad del Tecnológico de Monterrey. (2012). Índice de competitividad turística de los estados mexicanos. Instituto de Competitividad del Tecnológico de Monterrey, 2012. Recuperado de https://issuu. com/secretariadeturismodecolima/docs/_ndice_de_competitividad_tur_stica_de_los_estados

Kozak, M. y Martin, D. (2012). Tourism life cycle and sustainability analysis: Profit-focused strategies for mature destinations. Tourism Management, 3(1), 188-194. doi: 10.1016/ j.tourman.2011.03.001

Kristjánsdóttir, H. (2016). Can the Butler's tourist area cycle of evolution be applied to find the maximum tourism level? A Comparison of Norway and Iceland to other OECD countries. Scandinavian Journal of Hospitality and Tourism, 16(1), 61-75. doi: 10.1080/15022250.2015.1064325

La Plaza. (9 de mayo de 2017). La paciencia tiene límites en Ixtapa. Recuperado de http: / / laplazadiario.com/sociedad/la-paciencia-tiene-limites-en-ixtapa-the-digie-zone/

Lee, Y. y Weaver, D. (2014). The tourism area life cycle in Kim Yujeong Literary Village, Korea. Asia Pacific Journal of Tourism Research, 19, 181-198. doi: 10.1080/10941665.2012.735681 
López, V. M. (2011). ¿El mismo modelo para siempre? Comentarios sobre el ciclo de vida del área turística a partir de la experiencia de Bahías de Huatulco (México). Seminario Internacional Renovación y Reestructuración de Destinos Turísticos Consolidados del Litoral. Recuperado de https://rua.ua.es/dspace/bitstream/10045/20511/1/Seminario_Renovestur_01.pdf

López-Bonilla, J. M. y López-Bonilla, L. M. (2008). La capacidad de carga turística: revisión crítica de un instrumento de medida de sostenibilidad. El Periplo Sustentable, 15, 123-150. Recuperado de http://www.redalyc.org/articulo. oa?id=193415512006

Lundtorp, S. y Wanhill, S. (2001). La teoría del ciclo de vida del destino turístico: procesos de generación y estimación. Annals of Tourism Research en Español, 3(2), 364-383. Recuperado de https: / / dialnet.unirioja.es/revista/3785/V/3

Ma, M. y Hassink, R. (2013). An evolutionary perspective on tourism area development. Annals of Tourism Research, 41, 89-109. doi: 10.1016/j.annals.2013.07.001

Mckercher, B. (1999). A chaos approach to tourism. Tourism Management, 20, 425-434. doi: 10.1016/S0261-5177(99)00008-4

Mckercher, B. (2005). Are psychographics predictors of destination life cycles? Journal of Travel \& Tourism Marketing, 19(1), 49-55. doi: 10.1300/ J073v19n01_05

Michailidou, A. V., Vlachokostas, C., Moussiopoulos, N. y Maleka, D. (2016). Life cycle thinking used for assessing the environmental impacts of tourism activity for a Greek tourism destination. Journal of Cleaner Production, 111(B), 499-510. doi: 10.1016/j.jclepro.2015.09.099

Mombelli Pierini, M. I. (2010). La formación histórica del Corredor Acapulco-Zihuatanejo. Investigaciones Geográficas, 72, 120-138. Recuperado de http: / / www. scielo.org.mx/scielo.php?script=sci_arttext\&pid=S0188-46112010000200009

Mota Villanueva, A. (1995). El impacto urbano-regional del turismo. Caso de estudio Ixtapa-Zihuatanejo, Guerrero, del periodo 1970-1990 (Tesis de maestría). Recuperado de http://oreon.dgbiblio.unam.mx/F/SHUQLEVMQUNSNPSKMHICF48K7I32KTJ2VG9TGLSN86H62LK4JQ-26355?func=full-set-set\&set_ number $=019592 \&$ set_entry $=000006 \&$ format $=999$

Nexos. (1 de septiembre de 2009). Homicidios 1990-2007. Recuperado de http: / / www.nexos.com.mx/?p=13270

Núñez, P. y López, S. (2016). Desigualdades regionales en planificaciones desarrollistas. Una revisión del proceso de territorialización de Río Negro 19581976. Revista de Geografía Norte Grande, 63, 121-144. doi: 10.4067/S071834022016000100008

Proceso. (4 de julio de 1987). El Partenón en tierras ejidales. Recuperado de http://www.proceso.com.mx/146449/el-partenon-en-tierras-ejidales

Russell, R. y Faulkner, B. (1999). Movers and shakers: Chaos makers in tourism development. Tourism Management, 20, 411-423. doi: 10.1016/S02615177(99)00014-X

SECTUR. (2000). El turismo en la perspectiva 2020. Secretaría de Turismo. Recuperado de http://cedocvirtual.sectur.gob.mx/janium/Documentos/003559Pri0000.pdf 
SECTUR. (2012). Evaluación del desempeño de los destinos turísticos en el marco de los convenios de coordinación en materia de asignación de recursos. Recuperado de http://ictur.sectur.gob.mx/pdf/estudioseinvestigacion/estudiosfondosectorial/evaluaciondeldesempeno/2012_FSIDITT_EvaluacionCCRR_AnahuacNortee.pdf

SECTUR. (2013). Agendas de competitividad de los destinos turísticos de México. Ixtapa-Zihuatanejo, Guerrero. Recuperado de http://www.sectur.gob.mx/ wp-content/uploads/2015/02/PDF-Ixtapa-Zihuatanejo.pdf

Shida, O., Abdul, O., Badaruddin, M. y Azizi, B. (2015). Coastal resort life cycle: An overview of Tioman Island, Malaysia. Tourism Planning \& Development, 12(3), 266-280. doi: 10.1080/21568316.2014.947438

Soares, J. C., Gandara, J. M. e Ivars, J. (2012). Indicadores para analizar la evolución del ciclo de vida de los destinos turísticos litorales. Investigaciones Turísticas, 3, 19-38. doi: 10.14198/INTURI2012.3.02

Telfer, D. y Sharpley, R. (2016). Tourism and development in the developing world. Nueva York: Routledge.

U. S. Department Of State-Bureau of Consular Affairs. (8 de diciembre de 2016). Ixtapa-Zihuatanejo solo si se llega por vía aérea y se debe permanecer en las zonas turísticas. México Travel Warning U. S. Passports and International Travel. Recuperado de https://travel.state.gov/content/passports/en/ alertswarnings/mexico-travel-warning.html

Vera, J. F. y Baños, C. J. (2010). Renovación y reestructuración de los destinos turísticos consolidados del litoral: las prácticas recreativas en la evolución del espacio turístico. Boletín de la Asociación de Geógrafos Españoles, 53, 329-353.

Vera, F., López-Palomeque, F., Marchena, M., y Antón, S. (2013). Análisis territorial del turismo y planificación de destinos turísticos. Valencia: Tirant Humanidades.

Yang, J., Ryan, C., y Zhang, L. (2014). Sustaining culture and seeking a just destination: Governments, power and tension -a life-cycle approach to analyzing tourism development in an ethnic-inhabited scenic area in Xinjiang, China. Journal of Sustainable Tourism, 22(8), 1151-1174. doi: 10.1080/09669582.2014.924953

Zurita, J., Martínez, J. F. y Rodríguez, F. (2009). La crisis financiera y económica en el 2008. Origen y consecuencias en los Estados Unidos y México. El Cotidiano, 157, 17-27. 